Literature reference: von Schomberg, R. (2006 in print), 'The precautionary principle and its normative challenges', in E. Fisher, J. Jones and R. von Schomberg. (eds) (2006), Implementing the Precautionary Principle: Perspectives and Prospects, Cheltenham, UK and Northampton, MA, US: Edward Elgar, chapter 2. p19-42.

\title{
Chapter 2 The precautionary principle and its normative challenges
}

\author{
René von Schomberg*
}

\section{Introduction: the precautionary principle and deliberation}

This contribution aims to provide a comprehensive overview of the normative dimensions which need to be addressed while invoking the precautionary principle, implementing it under particular regulatory frameworks and applying it by taking particular measures. This contribution is written from the perspective of a policy analyst, and informed by an EU practice which is still evolving. In the second section, I will make an overview he normative challenges the precautionary principle faces in terms of deliberation at the levels of politics, policy making and the science-policy interface. In the third section, I will elaborate more specifically on one of the normative considerations which can trigger of the precautionary principle, namely 'a reasonable grounds for concern' which refers to the seriousness of particular threats under circumstances of scientific uncertainty. In the fourth section, I will elaborate on the normative standards for the acceptability of a particular level of protection of the environment or human health. I conclude with an operational definition of the precautionary principle on which all EU policy can, and should be based. The precautionary principle is a deliberative principle. Its application involves deliberation on a range of normative dimensions which need to be taken into account while making the principle operational in the public policy context. The term 'normative' refers here to all the prescriptive statements and or value judgements in contrast to factual scientific statements.

Table 2.1 Deliberation levels involving the progressive invocation, application and implementation of the precautionary principle with its normative dimensions 


\begin{tabular}{|c|c|c|c|c|}
\hline $\begin{array}{l}\text { Normative } \\
\text { dimension }\end{array}$ & $\begin{array}{c}\text { Main type//scope of } \\
\text { deliberation }\end{array}$ & $\begin{array}{c}\text { Type of operational } \\
\text { rationale }\end{array}$ & $\begin{array}{c}\text { Factors/normative } \\
\text { considerations to be } \\
\text { taken into account }\end{array}$ & $\begin{array}{c}\text { Normative } \\
\text { decision modi }\end{array}$ \\
\hline Political level & $\begin{array}{c}\text { broad political } \\
\text { debate }\end{array}$ & $\begin{array}{l}\text { Political consensus } \\
\text { on PP/Treaty basis }\end{array}$ & $\begin{array}{c}\text { Invocation of } \\
\text { precautionary } \\
\text { principle: scientific } \\
\text { uncertainty/threat of } \\
\text { adverse effects (two } \\
\text { trigger off factors) }\end{array}$ & $\begin{array}{l}\text { 'act rather than not } \\
\text { to act' }\end{array}$ \\
\hline Political level & $\begin{array}{c}\text { Choice of level of } \\
\text { protection/broad } \\
\text { societal./community } \\
\text { institutions }\end{array}$ & $\begin{array}{l}\text { Aim at high level of } \\
\text { protection }\end{array}$ & $\begin{array}{l}\text { High level of } \\
\text { protection, } \\
\text { consistency, non- } \\
\text { discrimination }\end{array}$ & $\begin{array}{l}\text { Defining/mapping } \\
\text { adverse effects }\end{array}$ \\
\hline Policy level & broad societal & cost/benefit analysis & $\begin{array}{c}\text { Health takes } \\
\text { precedence over } \\
\text { economic } \\
\text { considerations }\end{array}$ & $\begin{array}{l}\text { choice of selection } \\
\text { rules/priority } \\
\text { setting: e.g. } \\
\text { minimalizing costs, } \\
\text { max benefits, } \\
\text { priority to health etc }\end{array}$ \\
\hline Policy level & Political/societal & $\begin{array}{l}\text { Choice of } \\
\text { framework }\end{array}$ & $\begin{array}{l}\text { Implementation of } \\
\text { Precautionary } \\
\text { Principle }\end{array}$ & $\begin{array}{c}\text { Allocation of } \\
\text { burden of proof: } \\
\text { prior risk } \\
\text { assessment to } \\
\text { authorization, etc }\end{array}$ \\
\hline Policy level & Type of measures & $\begin{array}{c}\text { Enabling } \\
\text { precautionary } \\
\text { practice }\end{array}$ & $\begin{array}{l}\text { Proportionality } \\
\text { requirement } \\
\text { Application of } \\
\text { Precautionary } \\
\text { Principle }\end{array}$ & $\begin{array}{c}\text { 'least onerous } \\
\text { measure'/ measures } \\
\text { to enable } \\
\text { Precautionary/learni } \\
\text { ng practice: } \\
\text { monitoring, limited } \\
\text { licenses, } \\
\text { traceability/ } \\
\text { labelling }\end{array}$ \\
\hline $\begin{array}{c}\text { Science-policy } \\
\text { interface/Risk } \\
\text { management }\end{array}$ & Scientific/normative & $\begin{array}{l}\text { Identification of } \\
\text { state of affairs in } \\
\text { science/normative } \\
\text { qualification of } \\
\text { uncertainties }\end{array}$ & $\begin{array}{c}\text { Lack of knowledge/ } \\
\text { scientific } \\
\text { controversy: }\end{array}$ & $\begin{array}{c}\text { Normative } \\
\text { qualification of } \\
\text { available } \\
\text { information. } \\
\text { Relating the quality } \\
\text { of available } \\
\text { information } \\
\text { to 'degree of } \\
\text { seriousness' }\end{array}$ \\
\hline $\begin{array}{c}\text { Science- } \\
\text { society/policy } \\
\text { interface/risk } \\
\text { management }\end{array}$ & $\begin{array}{l}\text { Normative basis for } \\
\text { acceptability of } \\
\text { products/processes }\end{array}$ & $\begin{array}{l}\text { Identification of } \\
\text { transformable } \\
\text { standards }\end{array}$ & $\begin{array}{c}\text { Undefined } \\
\text { normative standards } \\
\text { for acceptability and } \\
\text { safety }\end{array}$ & $\begin{array}{c}\text { Choice of } \\
\text { transformable } \\
\text { standards: reduction } \\
\text { of biodiversity, } \\
\text { acceptable levels of } \\
\text { temperature rise etc. }\end{array}$ \\
\hline
\end{tabular}


In this contribution, I will identify and describe all these normative dimensions (see, for a summarized overview, table 2.1), which involve the invocation, implementation and application of the precautionary principle. Together, they constitute the operational definition of the precautionary principle to which I will conclude (box 1) at the end of this contribution. The normative dimensions consist of a particular scope of deliberation, constrained by particular normative decision modi, normative considerations and an operational rational typical for a particular level of deliberation. It should be noted that the different levels of deliberation neither represent a hierarchy nor necessarily a chronological sequence, as deliberation levels mutually inform and refer to each other: deliberation at each of the particular levels, can spark new deliberation at any of the other levels.

What follows is an ideal-type of description of all relevant deliberation levels in relation to the precautionary principle. The architectural framework of interrelating deliberation levels ensure public responsiveness and accountability of public actors and thereby contribute to the legitimacy of the decision-making process, whereby at the same time the different deliberation levels can ensure a particular quality of the outcome by positively selecting arguments in the light of the standards which are supposed to be met and also by negatively filtering out those arguments and preferences which fall below the (often demanding) constraints of the deliberation level concerned A positive filtering out of arguments towards a consensus is favoured by deliberative procedures, yet, they neither aim at, nor require consensus, and outcomes can be phrased in various terms such as, clarified decision agenda's or outcomes that allow a possible congruency of action of all actors concerned (Grin et al 2004),

Theorists of deliberative democracy work on the clarification of particular levels of deliberation within particular spheres of society. Neblo (2004) describes levels of public deliberation in terms of 'deliberative breakdown'. Fischer (2003) and Dryzek (1990) describe procedures of discursive politics. Grin et al (2004) define particular deliberations as practices of 'reflexive design'. I will elaborate here the deliberation levels with their particular normative dimensions, which need to be addressed while invoking the precautionary principle, implementing it under particular regulatory frameworks and applying it by taking particular measures.

\section{The normative political dimension of decision making}

\subsection{The invocation of the precautionary principle for a particular (policy) field}

At the initial level of considering the invocation of the precautionary principle, one has to distinguish between applying the precautionary principle in the context of a particular regulation, such as EU regulations concerning Genetically Modified Organisms (GMOs) and existing national laws, and the political decision to invoke the precautionary principle for a particular subject matter, (such as agricultural biotechnology, climate change, and the protection of the ozone layer), before any regulation or law is available. At this initial level, the decision is purely a political one. Even if there is no existing regulation regime existing in relation to the issue, such a political decision, is, and should be guided by a definition or general understanding of 
the precautionary principle which provides a rationale for action. Over recent years such a rationale and understanding have emerged from political discussions at the international level, and are reflected in several descriptions of the Principle in international agreements and, in the EU in (apart from the formal inclusion of the precautionary principle in the EU treaty) in court rulings of the European Court of Justice, Communications from the European Commission and most recently in the general principles and requirements of EU food law.

In any specific case, the rationale specifies particular circumstances, for which the possible invocation of the precautionary principle is specifically reserved and consists of two crucial elements:

1. The principle is to be applied in cases of potential adverse impacts on the environment or human health with serious consequences (thus implying that these consequences are unacceptable if true, see for the normative dimension concerning this 'seriousness of these consequences', further below).

2. Governmental action should be taken even though 'complete' scientific evidence is not available, there is ongoing scientific controversy, and/or there are disagreements about the lack of (scientific) knowledge. These circumstances are referred to as instances of scientific uncertainty. Scientific uncertainties arise because of controversies over the possibility of adverse effects to the environment or human health, their scope or their degree of seriousness.

The precautionary principle establishes a rationale for action: it substantially lowers the (threshold) level for action of governments (and possibly, depending on its national implementation, makes it easier for governments, when citizens or interest groups appeal to the precautionary principle in socio-political or judicial controversies). It represents a departure from the previous state of affairs where political actors could use or abuse a persistent dissent among scientists as a reason (or excuse), for not taking action at all ${ }^{1}$.

\subsection{Chosen level of Protection}

Every nation state has under international agreements the sovereign right to determine its own level of protection. For a particular nation, this level can, either be higher or lower than the level applied by other nations depending on its economic situation and socio-political priorities. With or without the precautionary principle, nations can thus determine such a general level of protection as they deem to be appropriate. Having the precautionary principle in place does not imply any new standard setting and therefore does not, for instance, imply the application of strict (or stricter) environmental or health standards: it only changes the procedure how nations can act when they want to implement their chosen levels of protection in the light of scientific uncertainty.

When it comes to protecting the environment or human health, the essential normative political choice is thus the determination of the chosen level of protection. However, the level of protection is not always very clearly determined or defined. The EU treaty states only that the level of protection should be "high" (e.g. for environment, consumer protection, human, animal and plant health $)^{2}$. It has been clarified that this does not necessarily have to be the highest level that is technically possible, and depending on the regulations involved, Community institutions do enjoy a broad discretion, in relation to the determination of the level of risk deemed unacceptable for society. Therefore, 'consistency' and 'non-discrimination' become relevant guidelines while invoking the 
precautionary principle and determining the chosen level of protection in a particular field and over a particular time-frame (EC, 2000). The precautionary principle can only legitimately be invoked, according to its above described rationale, if there is a threat that this chosen level of protection could be violated by particular products or activities. The proper application of the precautionary principle has to be seen in the light of this chosen level of protection. The choice of the level of protection determines the actual standards for health and the environment which should be employed. This normative/political choice will have to be applied for under all policies and is independent from the invocation of the precautionary principle.

In most cases, the level of protection is hardly ever defined in quantitative terms. Indeed in cases of significant scientific uncertainty, such quantification is not feasible.

Moreover, one is possibly not even sure whether anticipated adverse effects, actually pose a problem for our chosen level of protection (and therefore, possibly, should not be seen as adverse effect after all) or that one is not aware of effects which may indeed pose such problems. Some asked the 'so, what?' question when the spread of transgenes into the environment as a possible consequence of massive use of GMOs was defined as a possible unacceptable environmental effect (De Vries, 1999). In the context of Climate Change, for instance, there are no clearly defined standards for temperature rise which were to be seen as unacceptable: the uncertainty of the science is related to the uncertainty of what still could count as acceptable in terms of health and environmental effects. Invoking the precautionary principle, therefore, implies a delicate interplay between the choice of possible normative standards of acceptability and scientific assessments whether such standards would be violated without regulatory measures. While invoking the precautionary principle, one may in the light of acquisition of new knowledge, need to redefine the level of protection as well. In paragraph 2.4, I will elaborate further on the normative implications of the choice of standards. It is important to recollect at this point is that, the combination of an operational rationale of the precautionary principle and the obligation of maintaining a high level of protection (accompanied with possible non-quantified standards) sets the terms of the debate. At this stage of our deliberation, the question on the use of normative qualifiers which are connected to the effects which triggers the precautionary principle can already be clarified: the terms 'negative', 'serious' or 'significant' can not be operationalized in a public policy context, since their use would start a new discussion on their degree of seriousness, significance etc. The only possible proper qualifier is therefore the 'chosen level of protection', so that any possible infringement of that level can count as 'negative', 'serious', etc. I will use the general term 'adverse' effect in the sense that it implies an infringement of that level of protection.

\subsection{The choice and design of a particular framework}

The political dimension of the initial invocation is not fully exhausted by the mere existence of a constitutional or European Treaty based rationale for the precautionary principle. It is important to note that the precautionary principle is at the level of the EU treaty, a formal principle which implies that, depending on the area to which it will be applied, it will result in quite different types of environmental policies/regulations with a range of possible measures, which in themselves are in need of a proper justification. Although the basic rationale justifies pro-active action, the range of possible actions might vary considerably and it also raises the issue of applying the precautionary principle in a consistent, non-discriminatory and proportional way, for all areas 
concerned. The European Commission had to set up guidelines for the precautionary principle's application, among others, in order to tackle this issue, thereby ensuring that the precautionary principle can and will not be abused as a disguised protectionist trade measure and is compatible with the EU's international obligations such as those under the WTO and the UN (European Commission, 2000). Two of these guidelines stand out in relation to decisions with a normative political nature, namely the requirement of a proportional application of the precautionary principle and the requirement to examine the benefits and costs of action or lack of action The latter requirement has also been mentioned as a requirement for environmental policy in the Treaty on the European Union (European Union, article 172 of the title on the environment).

As far as the examination of the benefits and costs of action or inaction is concerned, it has to be taken into account that human health issues in the EU takes precedence over economic concerns ${ }^{3}$ and the Commission's guidelines clearly state that this examination should not be reduced to a pure economic weighing of costs and benefits (European Commission 2000 and European Council (2002)).

Christoforou (2003) rightly points out that this type of consideration does not play a decisive role in whether to adopt a precautionary principle based regulation or policy, but only in the actual choice or design of the framework. The choice and the design of the framework are part of political deliberations before they conclude in actual regulations and policies and this is why I see this aspect of the implementation of the precautionary principle at the normative political level.

The EU regulation on Genetically Modified Organisms, for example, shows a particular design of a precautionary regulatory framework. It established a case by case and step by step procedure (von Schomberg 1998). The framework does not prejudge the acceptability of individual GMO releases. This framework thereby takes a normative stand on GMOs as such, since it defines GMOs as a priori potentially hazardous, and shifts the burden of proof to the proponents of the activity, e.g. the applier for a GMO release has to demonstrate safety rather than that regulatory agencies or third parties have to demonstrate a risk ${ }^{4}$. The European Court has also confirmed that the legislation 'already makes provision, as one (italic by the author) of the possible ways of giving effect to the precautionary principle, for a procedure for prior authorisation of the products concerned' (Greenpeace France and Others, Judgement C 6/99, 21 March 2000).

\subsection{The choice of potential measures and the requirement of proportionality while implementing the precautionary principle}

Although the requirement of proportionality has its roots in the basic principles of Community Law, it will and can not be considered a trump card that could override the invocation of the precautionary principle. Whereas the cost/benefit analysis requirement constrains and guides the set up of the general regulatory framework or policy actions, the proportionality requirement relates in particular to the normative choice of possible alternative measures under such regulations or policy actions but does not eliminate the precautionary principle based justification of taking measures as such. According to Community law the principle of proportionality requires that measures adopted by Community institutions should not exceed the limits of what is appropriate and necessary in order to attain the legitimate objectives pursued by the legislation in 
question, and where there is a choice between several appropriate measures, recourse must be had to the least onerous, and the disadvantages caused must not be disproportionate to the aims pursued.

Thus the proportionate implementation of the precautionary principle is not aimed at categorical bans of products or processes (which might jeopardise the learning process) but certainly does not exclude such measures in individual cases. For instance, the EU recently withdrew particular antibiotics in feeding stuffs from the market while invoking the precautionary principle. A subsequent very revealing European Court of Justice ruling, concerning this antibiotics case, which included a judgement relating to both a contested interpretation of the precautionary principle and the principle of proportionality ${ }^{5}$, judged this ban as justified. The principle of proportionality has an impact on the choice of possible measures, and in the trade context, this could mean that one adopts measures that would be the least trade-restrictive. In general terms, the normative line of thinking here is that a proportionate application of the precautionary principle involves the least onerous measure while still attaining the legitimate objective. However, the European Court of Justice has clarified in the context of the judgement case Alpharma vs Council (see endnote 5) that a cost/benefit analysis should be seen as a particular expression of the principle of proportionality in cases involving risk management. I conclude here that because, in the case of the invocation of the precautionary principle, risk management is per definition involved (the invocation of the precautionary principle is a risk management decision in the EU context), the proportionality principle is integrated in the context of a broadly defined cost-benefit analysis. The outcome of such an analysis can, therefore, favour another option than the least onerous one in terms of restrictions to trade, depending on the normative decision rules (including priority setting) employed while exercising such an analysis ${ }^{6}$. The costs of particular measures can vary considerably in relation to the economic and social importance of the issue at stake as well as whether the invocation of the precautionary principle would lead to interference in planned activities or would involves various degrees of remediation. In the latter case, it also matters whether alternatives are available. For example in relation to banning substances that depleted the ozone layer there were alternative products while in contrast managing climate change requires changing entrenched current practices.

\section{The normative dimension of assessing the (epistemic) uncertainty concerning the use of scientific knowledge}

The precautionary principle is applied in the context of scientific controversy and the acquisition of new knowledge. In order to apply the precautionary principle properly, a clarification is needed as to what is precisely understood by 'scientific uncertainty' and what types of uncertainties are relevant for the invocation of the precautionary principle. In this section I am particularly concerned with the issue how the normative qualifier 'reasonable grounds for concern' can be used for triggering of the precautionary principle. Any scientific advice is surrounded by some degree of uncertainty and this in itself is not a reason for, nor usually leads to, the invocation of the precautionary principle. In the table 2.2 below, I categorise the types of uncertainties whereby I build upon, but significantly modify, the work of Stirling (1999), Renn and co-authors (2003) 
in this area. Table 2.2 presents an overview of the state of affairs in science and the corresponding responses by risk management and the appropriate regulatory framework.

Table 2.2 Overview of State of Affairs in Science and the possible corresponding responses by Risk Management

\begin{tabular}{|c|c|c|}
\hline Circumstances & $\begin{array}{c}\text { State of Affairs in } \\
\text { Science }\end{array}$ & $\begin{array}{c}\text { Policy Framework/Regulatory } \\
\text { action/ Examples }\end{array}$ \\
\hline Risk & $\begin{array}{c}\text { Known effects, } \\
\text { /quantifiable } \\
\text { probabilities, } \\
\text { uncertainties may have } \\
\text { statistical (e.g. } \\
\text { stochastically) nature }\end{array}$ & $\begin{array}{c}\text { Risk Management by defining } \\
\text { thresholds on the basis of chosen level } \\
\text { of protection, exercising prevention, } \\
\text { minimalization of risk and or } \\
\text { precautionary minimalization of risks } \\
\text { by feasible management measures: } \\
\text { applying the ALARA principle etc. }\end{array}$ \\
\hline $\begin{array}{c}\text { Unquantifiable } \\
\text { Risk, lack of } \\
\text { knowledge }\end{array}$ & $\begin{array}{c}\text { Known effects/unknown } \\
\text { or uncertain cause-effect } \\
\text { relations, therefore } \\
\text { unknown probabilities }\end{array}$ & $\begin{array}{c}\text { Antibiotics in feeding stuff/Protection } \\
\text { of the North Sea. Invocation of } \\
\text { precautionary principle is justified; } \\
\text { preventive measures to take away the } \\
\text { possible causes can be justified. }\end{array}$ \\
\hline $\begin{array}{c}\text { Epistemic } \\
\text { uncertainty: } \\
\text { scientific } \\
\text { controversies, lack } \\
\text { of knowledge) }\end{array}$ & $\begin{array}{c}\text { Unknown scope of } \\
\text { effects, however, degree } \\
\text { and or nature of their } \\
\text { seriousness' (in relation } \\
\text { to the chosen level of } \\
\text { protection) can only be } \\
\text { estimated in qualitative } \\
\text { terms. }\end{array}$ & $\begin{array}{c}\text { Invocation of the precautionary } \\
\text { principle is justified: example: GMOs, } \\
\text { Climate Change, Ozone depletion }\end{array}$ \\
\hline $\begin{array}{c}\text { Hypothetical } \\
\text { effect/ imaginary } \\
\text { risk }\end{array}$ & $\begin{array}{c}\text { Arguments on the basis } \\
\text { of a fully conjectural } \\
\text { knowledge base, no } \\
\text { scientific indication for } \\
\text { their possible occurrence }\end{array}$ & $\begin{array}{c}\text { Invocation of precautionary principle } \\
\text { is not justified. }\end{array}$ \\
\hline
\end{tabular}

In accordance with what is summarised in table 2.2, we can distinguish four circumstances. The first type of circumstances relate to 'hypothetical effects and imaginary risk'. A conjectural approach which involves the identification of a purely hypothetical risk can not be considered for the invocation of the precautionary principle. Both the EC guidelines on the precautionary principle and the ruling of the European Court of Justice (T70/99 for example) exclude such situations and confirm that any invocation of the precautionary principle should start with a scientific examination of the issue. It involves a mapping or identification of the possible adverse effects and is subsequently followed by a risk assessment. It is acknowledged that such an assessment is not necessarily either complete or conclusive in all its details. This scientific examination can also include or build upon minority views within the scientific field ${ }^{7}$. Yet, the invocation of the precautionary principle is always scientifically informed ${ }^{8}$ and, procedurally, it is mandatory to have such an examination available before invoking the precautionary principle. 
A second type of circumstances which can be distinguished relates to the normal situation of a defined risk, whereby the level of protection is defined, and the risk (e.g. the probability of the occurrence of the adverse effects multiplied by their impact) can be quantified. In such situations, the policy makers can respond with a normal risk management approach whereby, for example, thresholds can be set, risks can be either minimised or kept below a certain level, and precautionary measures can be taken to keep particular effects well below particular thresholds by employing the ALARA(as low as reasonably achievable) principle. The invocation of the precautionary principle is neither necessary nor relevant. ${ }^{9}$ Because there is scientific consolidated basis concerning the adverse effects in question, one can act with preventive (in contrast to precautionary) interventions.

The situation becomes completely different when one encounters a third type of situation in which one can not fully rely on the scientific information system as such when it comes to the estimation of possible adverse effects. This is notably the case when an epistemic debate is going on in science ${ }^{10}$ : e.g. disciplines use competing models or analogies or basic assumptions to disclose the subject matter under investigation in order to acquire new knowledge. In the case of (long-term) effects of the introduction of GMOs, for instance, biotechnologists usually refer, by analogy, to the practice of conventional plant breeding as a basis for making 'predictions' concerning their risks. Ecologists, on the contrary refer, also by analogy, to experience based on the introduction of particular species into new environments (thereby causing 'problem' plants and pests) (Von Schomberg, 1993). This debate went even so far that representatives of the different disciplines dismissed the relevance of each others' knowledge base for the actual assessment of risks. The epistemic debate concerning the (long) term effects in terms of their predictability will need decades to be completely resolved: Both the analogies of the ecologists and biotechnologists are plausible, but refer to a completely different (potential) scientific information base that still needs to be disclosed by ongoing research. The possible effects of individual releases (although one needs to take into account the accumulation of many releases over time) may not be either fully identifiable, nor be known in their scope (in terms of possible negative indirect-effects, long term or delayed effects). However these effects might be supervisable and practical management and monitoring practices could enable an early identification of unexpected events. Also their degree of seriousness can be identified to some extent. Particular effects may be irreversible, since if transgenes are in the environment, then they can not be (easily) retrieved. The situation is different from a classical risk management situation: a precautionary approach can be justified.

Less dramatic in terms of scientific debate, but with similar relevance for the invocation of the precautionary principle, are cases relating to a fourth type of circumstance when particular cause-effect relationships can not be scientifically established while at the same time the adverse effects are known. The withdrawal of the use of particular antibiotics in feeding stuffs as well as the protection of the North Sea (dumping of waste) provides us with such an example.

The overview of these four types of circumstances establishes the need to have an assessment of the state of affairs in science and type of uncertainties involved. Drawing 
the border line, between classical risk management practice and the situation of a purely conjectural risk involves making normative choices which need to be made explicit. But even more importantly, in the case of epistemic uncertainty, a normative relationship between the nature of the uncertainties and the possible adverse effects needs to established in order to justify policy and regulatory intervention. In assessing the uncertainty involved, normative qualifiers come into play while invoking the precautionary principle. It does make a difference if the invocation of the precautionary principle needs to be established in relation to the anticipated adverse effects: a 'reasonable grounds for concern' (EC communication on the precautionary principle), the identification of possible harmful effects on health following an assessment of available information (Regulation EC 178/2002, general principles and requirements of food law) or 'balance of evidence'(Intergovernmental Panel for Climate Change (2001) or 'sufficient evidence for safety'. However it is difficult to outline precisely the normative constraints of the type of scientific information needed which is 'sufficient' to trigger it off. Some argue that there is a 'degree' of likelihood associated with those qualifiers ${ }^{11}$. I find it; however misleading that one would be able to assess the 'risk' of false positives e.g. where unnecessary action will be taken on what later will turn out to be fears rather than 'facts. The uncertainties which are usually involved, are precisely related to the impossibility of assigning a 'degree' of likelihood to the anticipated adverse effects. Some of the qualifiers belong, in my view, to the vocabulary of risk regulation (such as 'sufficient evidence' or 'identified' risk) rather than to precautionary practice. I suggest to relate the normative qualifiers to the 'quality of the available information'. The 'quality of the information' is not determined by the 'amount or degree' of uncertainty but relates especially to what type of information is known or should be known and of which one is ignorant: for example the knowledge concerning established cause-effect relationships and the degree of necessity to know those relationships in order to make a judgement. The qualifier 'reasonable grounds for concern' as employed by the EC guidelines makes, in my view, no prejudice about the degree of likelihood, but this qualifier relates in fact to a judgement on the quality of the available information. It is, therefore, misleading to situate this qualifier in a scale of possible 'levels', or 'degrees' of proof as Harremoes has suggested. It becomes even more complicated to take the linguistic connotations of suggested 'degrees' or 'levels' into account. Some may feel that this degree needs to be balanced against the degree of seriousness of anticipated effects. It suggests that a very serious violation of our chosen level of protection would lower our requirements concerning the quality of available scientific information and arguments. This is obviously a particular normative choice which needs to be justified in relation to possible other choices.

\section{The choice of transformable normative standards under particular regulatory frameworks which define the societal acceptability of particular emissions/products}

Precautionary regulation always implies the regulation of a subject matter on the basis of standards that remain open for discussion. The regulation itself cannot define these standards. This is a completely new dimension in international environmental policy and not always appreciated. I will illustrate this point again on the case of GMOs. The European directive on GMOs (European Communities, 2001, article 4) states: 'Member States shall, in accordance with the precautionary principle, ensure that all 
appropriate measures are taken to avoid adverse effects on human health and the environment which might arise from the deliberate release or the placing on the market of GMOs' The directive leaves open what precisely can be considered as an 'adverse effect on human health and the environment'. The directive also leaves open what could be 'a sufficient demonstration of safety', let alone that it requires to substantialize the degree of uncertainty which could justify restricted use or a ban of a particular GMO. The combination of a case by case evaluation and the absence of fixed standards for evaluating these cases provide the background for ongoing deliberations at national level and in scientific advisory committees.

Without a normative standard, however, it is impossible to draw a valid conclusion on the acceptability of a product or a release. Therefore, risk managers have to make normative assumptions about which products are acceptable or not acceptable. In the case of GMOs, the implicit strategy has been to make an appeal to a conventional norm, that is to say a standard which would be acceptable because one can be certain it is widely accepted and uncontroversial (and would fit to our chosen 'high level of protection'). What kind of standard would that be? The Dutch advisory committee on genetic modification (COGEM) made the following statements in the evaluation of the application concerning an herbicide resistant oil-seed rape in June 1994 (COGEM, 1994): 'outcrossing transgenic characteristics will not cause a persistently negative impact on the environment [and] outcrossing the gene and its property male sterility ... will not lead to a persistently unacceptable impact of these relatives on the composition of varieties in natural vegetation'.

To draw a conclusion on the acceptability of an impact, one has to use phrases with normative implications such as 'negative impact' or 'unacceptable impact'. In this case, the advisory committee assumed that a conventional standard, and therefore a non-controversial reference point, would be the 'natural situation' itself. It is assumed that so long as any impact would be an impact which could be counter-balanced by nature, which would allow nature to return to its original situation, it would be an 'acceptable impact'. Generally, this conclusion, which at first glance seems quite uncontroversial, implies that any process or impact caused by releases or new agricultural practices would be acceptable if one finds that such a process or impact would be an instance occurring in nature itself. Indeed, advisory committees came to the conclusion that herbicide-resistant genes, for instance, are widespread in the natural environment and that, therefore, a possible spread of these genes caused by man-made varieties would be an acceptable phenomenon, comparable with existing natural processes.

However unproblematic this appeal to a conventional norm seems to be, it soon runs into difficulties when one tries to apply this normative reference point, in diverse cases over time. Our knowledge of nature is far from complete and our perception of nature changes over time while our scientific knowledge grows and our cultural values change. Until several years ago, for example, the general belief was that 'gene flow' is not a natural phenomenon (and therefore unacceptable), but now it has been discovered that it occurs under particular circumstance in nature as well, which would turn it again into an acceptable impact. (provided one agrees that what happens in nature is always acceptable....) So, our further analysis turns our 'convention' into a transformable 
normative standard, which depends on (and evolves synchronically with) the historical change in our perception of nature.

If one analyses the case of GMOs in more detail (see Von Schomberg (1998), one will find that 'reduction of biodiversity' is not the only transformable standard which can be employed while assessing the acceptability of releases. Alternative standards (equally transformable in nature, on which I can elaborate here) are: 'Comparison with conventional agricultural practices' ${ }^{12}$, that is to say, anything that does not yield an impact substantially different from the impact of existing agricultural practices would account for an 'acceptable' release.

'Compatibility with sustainable agricultural practice', that is to say only those releases which could be integrated in a sustainable agricultural practice would account for an 'acceptable release'.

In the European context, conflicting scientific assessments among scientific advisory bodies can be traced to the normative choice of one those standards and the way in which these standard were applied, whereas they hardly relate to the probability of major environmental impacts. Consensus on such an issue seems a matter of agreeing on the standard(s) to be used. Up till now, precautionary regulation has probably relied too much on an implicit use of such standards. The obvious solution for the problem is to embark on an open discussion on such standards. I conclude that an undefined high level of protection in combination with a precautionary regulatory framework forces risk managers to look out for standards which are 'transformable' by nature in order to make the necessary normative conclusions concerning adverse effects. Analysis of other complex scientific issues, such as climate change, the management of large ecosystems etc involve always the use of such transformable standards. This is a crucial difference with the context of classical risk management issues under which standards can be predefined.

\section{Conclusions and Outlook}

Precautionary measures are provisional measures by nature, and need to be regularly reviewed when scientific information either calls for relaxation or strengthening of those measures. Within the EU context, these provisional measures do not have a prefixed 'expiry' date: one can only lift precautionary measures if scientific knowledge has progressed to a point that one would be able to translate (former) uncertainties in terms of risk and adverse effects in terms of defined, consensual levels of harm/damage. Precautionary frameworks facilitate in particular deliberation at the science/policy/society interfaces to which risk management is fully connected. Applying the precautionary principle is to be seen as a normative risk management exercise which builds upon scientific risk assessments ${ }^{13}$. An ongoing scientific and normative deliberation at the science/policy interface involves a shift in science centred debates on the probability of risks towards a science informed debate on uncertainties and plausible adverse effects: this means that decisions should not only be based on available data but on a broad scientific knowledge base including a variety of scientific disciplines.

Above I have elaborated the essential normative dimensions of the invocation and application of the precautionary principle. I propose to distinguish between risk-based 
regulation (which applies to the classical situation of a defined risk) and uncertaintybased regulation under a precautionary regulatory framework (see table 2.3.). The table shows, in accordance with our discussion above, that there is actually an uncertaintybased regulation assumed under a precautionary regulatory framework ${ }^{14}$. The shift from risk-based regulation to uncertainty-based regulation under a precautionary regulatory framework needs a new justification since the vocabulary of a risk assessment model is inappropriate for that type of practice.

Table2. 3 Characteristics of regulatory systems

\begin{tabular}{|c|c|}
\hline Risk-based regulation & Uncertainty-based regulation \\
\hline identifying risks & $\begin{array}{l}\text { assessing uncertainties/state of affairs in } \\
\text { science }\end{array}$ \\
\hline applying standards of acceptable risks & $\begin{array}{l}\text { applying transformable (deliberation- } \\
\text { based) standards of acceptable } \\
\text { uncertainties }\end{array}$ \\
\hline applying definitions of harm & $\begin{array}{c}\text { appealing to normative transformable } \\
\text { standards }\end{array}$ \\
\hline $\begin{array}{l}\text { calculating the chance of occurrence of } \\
\text { probable effects }\end{array}$ & $\begin{array}{l}\text { assessing the plausibility of possible } \\
\text { adverse effects }\end{array}$ \\
\hline policy objective: minimizing risks; etc & $\begin{array}{c}\text { policy objective: reducing uncertainties; } \\
\text { enabling precautionary and learning } \\
\text { practice etc }\end{array}$ \\
\hline $\begin{array}{l}\text { possibility of avoidance of predictable } \\
\text { long-term effects by prevention }\end{array}$ & $\begin{array}{l}\text { prospective long-term effects can only be } \\
\text { identified to some extent, precautionary } \\
\text { measures such as monitoring could } \\
\text { enable the early identification of adverse } \\
\text { effects over time }\end{array}$ \\
\hline
\end{tabular}

The application of transformable standards is an inherently discursive process. On each single case such standards need to be applied over and over again, with possible different outcomes over time. These normative standards reflect and should reflect the chosen 'aim of high level of protection' as enshrined in the EU treaty. In a certain sense, this is also a transformable standard in itself, since what is considered as 'high', changes over time and relates to socio-economic circumstances. The impossibility to define fixed standards and to operate with necessary open standards is a positive feature of a regulatory framework in democratic societies. It invites citizens to discuss those standards as they can not be solely defined by risk managers and scientific advisers. The challenge is to interconnect those standards with the discussions within scientific committees, the risk management level and society at large. Technology assessment and technology foresight exercises can thereby be helpful to feed such a deliberative process. Expertise needs also to be extended with forms of knowledge assessments, to assess the normative quality of the information, in order to identify the meaning of particular uncertainties, the quality of the available knowledge (which includes 
knowledge beyond the area of science), and their relevance for policy(Von Schomberg et al, 2005).

In the mean time, a significant progress has been achieved in dealing with scientific uncertainty by taking into account all relevant scientific disciplines while asking for scientific advice. (See among others, the EC guidelines on democratising expertise (EC 2002)). Institutional innovations have also taken place: the regulation EC 178/2002 which establishes the European Food Safety Authority (EFSA) foresees, among others, in particular procedures when scientific opinions diverge, entailing an obligation to cooperate together with the relevant body (when the body with the diverging view is a community body) to work together with a view on clarifying the issue and an obligation to publish the joint findings in a publicly accessible document. There is also an obligation of the authority to actively identify and contact non-community bodies with a diverging view, in order to share the information.

There is also a growing recognition of the normative challenges involved while invoking the precautionary principle. Under particular precautionary regulatory frameworks, such as the regulation of the European Parliament and of the Council on genetically modified food and feed, it is for example recognised 'that a risk assessment alone cannot provide all the information on which a risk management decision should be based, and that other legitimate factors relevant to the matter under consideration may be taken into account' (European Communities (2003), paragraph 32 of the preamble).

I conclude by summarising that the invocation, implementation and application of the precautionary principle follows a progressive line of different levels of deliberations (which obviously can be interconnected to each other but are distinguished here for analytical purposes). I have listed these levels of deliberation in table 2.1. The table provides a model for guiding all the relevant normative levels of deliberation which are all needed in order to eventually make the legitimate conclusions on the acceptability of products or processes. The table provides a progressive line of those levels of deliberations from the initial invocation of the precautionary principle at the political level down to level of risk management decisions but at the same time show their interrelatedness. Although table 2.1 may suggest a particular sequence in an ideal world (e.g. from the political level downwards), practically the 'entry' stage can be at any level and those levels do not represent a hierarchy in any sense. Practices which were formerly not based on the precautionary principle may become based on the precautionary principle by discussions which arise at the science/policy interface. I conclude with the (ultimate?) overall definition of the precautionary principle (rather than a specified definition of the precautionary principle for a particular area, such as the environment, human health or food safety) while remaining within the wide scope and limits of the recent rulings of the European Court of Justice, the broad EU endorsement of the European Guidelines on the precautionary principle, and international obligations under international Treaties such as those under the WTO and the UN. The definition contains all the normative dimensions discussed in this contribution. Box 1 contains the definition of the precautionary principle and Box 2 contains the explanation of the terminology. 
Box 2.1 Policy definition of the precautionary principle

Where, following an assessment of available scientific information, there are reasonable grounds for concern for the possibility of adverse effects but scientific uncertainty persists, provisional risk management measures based on a broad cost/benefit analysis whereby priority will be given to human health and the environment, necessary to ensure the chosen high level of protection in the Community and proportionate to this level of protection, may be adopted, pending further scientific information for a more comprehensive risk assessment, without having to wait until the reality and seriousness of those adverse effects become fully apparent.

Box 2.2 Explanation of the terminology of the definition of the precautionary principle

Where, following an assessment of available scientific information: this formulates the formal obligation to have a scientific assessment.

There are reasonable grounds for concern: normative qualifier employed in the EC guidelines on the precautionary principle as an requirement to relate the quality of the available information (rather than 'degree of uncertainty') to seriousness of possible adverse effects.

the possibility of adverse effects: adverse effects, is a general formula for effects inconsistent with the chosen level of protection in relation to health, environment, etc. It concerns one of two basic trigger of factors for the invocation of the PP. The term can be replaced by, for example, 'harmful effect for health' for the area of food. (this wording has indeed been incorporated as a definition of the precautionary principle in the general principles of EU food law)

but scientific uncertainty exists: refers to the other trigger off factor concerning the invocation of the PP

Provisional risk management measures: refers to the mandatory provisional nature of measures.

the chosen high level of protection in the Community: relates to Community situation, can be replaced by other definitions in other societal contexts or renewed definitions in the Treaty or constitution.

Proportionate to this level of protection: relates to the mandatory requirement of the application of the principle in accordance with Community law and as an expression of or part of a general cost/benefit analysis (as required by the EC guidelines on the PP)

following a cost benefit analysis, whereby priority will be given to human health and the environment: reflects political priorities as defined by the Nice Resolution, but which are also enshrined in the Treaty as clarified by rulings of the European Court of Justice. The Nice Resolution called also for a broad cost benefit analysis. This formula can be left out under particular regulations since this analysis will be conducted with a view on the architectural framework of such a regulation.

pending further scientific information for a more comprehensive risk assessment: expresses the mandatory character of an ongoing risk assessment and the accumulation of scientific knowledge. The expression 'comprehensive' is preferable over 'more objective' as used in the context of the SPS agreement and is based on a particular view of science which is not the contemporary one. It articulates also the fact that these assessments do not necessarily have to be, or can be, complete by nature.

may be adopted.... without having to wait until the reality and seriousness of those adverse effects become fully apparent: follows the wording of a recent and above cited 
Court ruling and expresses the general understanding and rationale of the PP: this wording legitimates early action by government. The formulation of the $\mathrm{PP}$, as principle 15 in Agenda 21, seems more compelling: (..)no reason for postponing cost-effective measures to prevent(...)'.

\section{References}

Agenda 21 (1992), Agenda 21 and the UNCED Proceedings, vol 1. Ed. by Nicholas Robinson. New York

Christoforou, T. (2003), The Precautionary principle and democratising expertise: a European Legal Perspective, in Science and Public Policy, volume 30, June 2003, p. 205-213

Convention on Biological Diversity (2000), Internet: http://wwwi.biodiv.org

COGEM (Dutch Committee on Genetic Modification) (2004), The Hague: reference nr C/UK/94/M1/1 public register in the library of the Dutch Ministry for the Environment (VROM)

Dryzek, J.S. (1990), Discursive democracy: politics, policy, and political science, Cambridge: Cambridge University Press

European Commission (2000), Communication from the Commission on the Precautionary Principle, (COM 2000/001), Brussels

European Commission (2002), Communication from the commission on the collection and use of expertise by the commission: principles and guidelines 'Improving the knowledge base for better policies' COM (2002) 713 final, Brussels.

European Communities (2001), Directive 2001/18/EC of the European Parliament and of the Council of 12 March 2001 on the deliberate release into the environment of genetically modified organisms and repealing Council directive 90/220/EECCommission Declaration, Official Journal of the European Communities , L 106, 17 April 2001

European Communities (2002), Regulation (EC) 178/2002 of the European Parliament and of the Council of 28 January 2002 laying down the general principles and requirements of food law, establishing the European Food Safety Authority and laying down procedures in matters of food safety, Official Journal of the European Communities, L 31, 1 February 2002.

European Communities (2003), Regulation (EC) 1829/2003 of the European Parliament and of the Council of 22 September 2003 on genetically modified food and feed, Official Journal of the European Union, L268/1, 18 October 2003 
European Union (2002), European Union consolidated versions of the treaty on European Union and of the treaty establishing the European community, Official Journal of the European Union, C325, 24 December 2002, Title XIX, article 174, paragraph 2 and 3.

European Council, (2000), Resolution on the Precautionary Principle, Brussels The European Environment Agency (2002), Late Lessons from Early Warning, Copenhagen

Fischer, F. (2003), Reframing Public Policy. Discursive Politics and Deliberative Practices. Oxford: Oxford University Press

Grin, J., Felix, F., Bos B. and Spoelstra S. (2004), Practices for reflexive design: lessons from a Dutch programme on sustainable agriculture, Int. J. Foresight and Innovation Policy. Vol 1. Nos 1/2, pp.126-149.

Habermas, J (1996), Between Facts and Norms. Contributions to a discourse theory of Law and Democracy MA: MIT Press.

Intergovernmental Panel for Climate Change (2001), Summary for Policy Makers, Shang Hai.

Kriebel D. et al (2003), The Precautionary Principle in Environmental Science', Environmental Health Perspectives, vol. 109,No 9, Sept 2003

Lawless, W. F. (2004), DOE's policy of consensus seeking versus truth seeking in traditional American democracy. WM'04 Conference February 29-March 4, 2004, Tuscon, AZ

Neblo, M.A. (2004), Thinking through Democracy: Deliberative Politics in Theory \& Practice, Paper presented at the Conference on 'Empirical Approaches to Deliberative Politics’ European University Institute, Firenze, 21-22 May 2004

Renn et al (2003), Regulatory Strategies and Research Needs to compose and specify a European Policy on the Application of the Precautionary Principle (Precaupri), project financed as a STRATA under the Improving Human Potential Programme of the EC, unpublished manuscript

Stirling (1999), On Science and Precaution in the Management of Technological Risk, IPTS, Seville

Schomberg, Rene von (ed.) (1993), Science, Politics and Morality. Scientific Uncertainty and Decision making, Rene von Schomberg (ed.), Dordrecht: Kluwer Academic Publishers, 1993

Schomberg, Rene von (1995), Der Rationale Umgang mit Unsicherheit, Frankfurt am 
Main: Peter Lang, 1995

Schomberg, Rene von (1998), An appraisal of the working in practice of directive 90/220 concerning the deliberate release of genetically modified organisms in the environment", Luxembourg: STOA report of the European Parliament. Free internet-download at http://www.europarl.eu.int/stoa/publi/default_en.htm

Schomberg, Rene von (2002), 'The Erosion of Valuespheres: The Ways in which Society Copes with Scientific, Moral and Ethical Uncertainty' in: Discourse and Democracy. Essays on Habermas'Between Fact and Norms, edited by Von Schomberg and Baynes, State University of New York Press, Albany, 2002

Schomberg, René von, Angela Guimarães Pereira and Silvio Funtowicz (2005). Deliberating Foresight-Knowledge for Policy and Foresight- Knowledge Assessment., European Commission, Directorate General for Research, also:

http://www.cordis.lu/foresight/working.htmVos, Ellen (2004), 'Antibiotics, the Precautionary Principle and the Court of First Instance', Maastricht Journal of European and Comparative Law, 11, 187-200.

Vries, Gerard de (1999), Commission Genetic Modification, Proceedings second international work CCRO workshop, Bilthoven, Netherlands, 1999, p 125-136

\section{Cases}

Case T-70/99 Alpharma v. Council [2002] ECR II-3495

Cases C-157/96 and C-180/96. European Court of first Instance, Judgements of 5 May 1998

Case C 6/99, Greenpeace France and Others, European Court of First Instance, Judgement of 21 March 2000

\section{Endnotes}

* René von Schomberg is at the European Commission, Directorate General for Research, Science and Technology Foresight Unit. The views expressed here are those of the author and may not in any circumstances be regarded as stating an official position of the European Commission. Email:Rene.von-schomberg@cec.eu.int. I want to thank Elizabeth Fisher, William Lawless and an anonymous reviewer for comments on an earlier draft of this paper.

${ }^{1}$ Judgements of 5 May 1998, cases C-157/96 and C-180/96, rulings of the European Court of Justice concerning its judgement on the validity of the European Commission's decision banning the exportation of beef from the United Kingdom to reduce the risk of BSE transmission, reveals a similar rationale for action based on the PP, for the human health area: 'Where there is uncertainty as to the existence or extent of risks to human health, the institutions may take protective measures without having to wait until the reality and seriousness of those risks become fully apparent': 
${ }^{2}$ 'Community policy on the environment shall aim at a high level of protection taking into account the diversity of situations in the various regions of the Community', European Union (2002), article 174, paragraph 2

${ }^{3}$ Order of 30 June 1999, Case T 70/99, Alpharma vs Council: 'requirements linked to the protection of public health should undoubtedly be given greater weight that economic considerations'

${ }^{4}$ EU regulation concerning chemicals (under loud protest of EU's industry) moves in a similar direction with a mandatory risk assessment to be produced by the applicant.

5 Judgment Case T-70/99, Alpharma vs Council [2002] ECR II-3495. This judgement and the ongoing interpretations of the proportionality principle are well reflected in Vos (2004).

${ }^{6}$ I can not enter here into details on the possible normative choice of options while choosing normative selection rules such as: 'maximizing benefits while minimising costs/disadvantages', or only 'minimizing costs/disadvantages' and using priorities such as 'avoiding health effects' or 'irreversible effects'.

${ }^{7}$ Minority views, however, do not need to be seen in isolation. Scientific evaluations work best in the context of independent scientific peer review, as demonstrated, for example, by Lawless and Grayson (2004). It speaks for itself that those scientific evaluations need to be done in a transparent way and that the results are publicly accessible.

${ }^{8}$ I prefer the use of the terminology 'scientifically informed' over 'science-based' which has the connotations that the precautionary principle would have only a factual basis. It also seems to refer to a US context and the mere wish to copy US practice, rather than it really relates to actual European reality. In this article, I argue in fact the contrary position, namely that it has a normative basis but, at the same time, is (on a mandatory basis) scientifically informed and can only be triggered of by scientific assessments.

${ }^{9}$ Note that one can take 'precautionary' measures without invoking the precautionary principle

${ }^{10}$ I have characterized the nature of 'epistemic debates' in von Schomberg (1995). A short overview appeared in Schomberg (1993).

11 This argument developed by Poul Harremoes is partially reflected in a table with 'levels of proof' in European Environment Agency (2002)

12 There seems to be a sort of institutional preference to compare alternatives with current practice. However, before taking current practice as the default norm or benchmark, one needs to evaluate whether future developments do not allow us to get to policies which retrospectively define current practices as insufficient. The 'sustainability' requirement inherently links to such discussions. 
${ }^{13}$ It is therefore not imaginable that a proper invocation/implementation and application of the precautionary principle is based solely on a 'perceived' risk. I can not enter here in the discussion on the distinction between actual vs, perceived risks. Under my framework neither 'perception' is something what is entirely defined by the 'lay public' nor is any 'actual' risk element entirely defined by experts. Since the application of the precautionary principle starts with a (yet incomplete) scientific risk assessment, any 'perceptional' element is already initiated with a scientific content.

${ }^{14}$ Regulators and political actors often justify this type of regulation still in terms of a risk-based regulation. However, no one can either justify how to translate uncertainty to risk, or justify how to translate normative transformable standards to definitions of harm. 